\title{
Seronegative dementia paralytica: report of a case
}

\author{
L. CH'IEN, B. M. HATHAWAY ${ }^{2}$, AND C. W. ISRAEL \\ From the Division of Neurology, Department of Medicine, University of Alabama Medical Center; Department \\ of Pathology, University of Alabama Medical Center, and of Ophthalmology, Bascom Palmer Eye Institute, \\ Miami, Florida, U.S.A.
}

SUMMARY Dementia paralytica may present diagnostic difficulties when routine serological test using a non-treponemal antigen is non-reactive. We present an illustrative demented patient who initially had negative VDRL test both in his serum and cerebrospinal fluid. However, the brain biopsy specimen showed active meningoencephalitis. By special staining technique, a spiral organism was found in the brain exhibiting morphology perfectly compatible with treponema pallidum. Later in the course, the VDRL became reactive in the blood but remained non-reactive in the cerebrospinal fluid. On the basis of the experience of other workers in the field and ours with this patient, we advise the use of FTA-ABS test as a screening procedure in patients with neurological problems $\dot{\omega}$ of possible syphilitic origin. We urge further research in this field.

Dementia paralytica may present diagnostic difficulties, which increase when a routine serological test for syphilis using a nontreponemal antigen yields a negative result in a patient with disease of the central nervous system. Specific treponemal tests yield more sensitive results in late syphilis; these, however, are usually done only when the initial reagin test is positive or equivocal, unless the history, clinical signs, or other evidence arouses the clinician's suspicion. Because of the negative reagin test in the patient here reported, diagnosis was delayed.

Still another problem confronts the clinician: should one take great pains to obtain a definitive diagnosis in a grossly demented patient whose disease appears irreversible? In our patient, diagnosis rested on a brain biopsy since the family demanded a tissue diagnosis to exclude the presence of familial neuropsychiatric disease.

CASE REPORT

On 13 November 1968 we first saw this 38-year-old Caucasian man who was referred to our hospital because

'This work was supported (in part) by a Special Fellowship 2-F111633-04 VSN from the National Institute of Neurological Diseases and Blindness, Public Health Service.

${ }^{2}$ Address for reprints: Dr. Hathaway, Department of Pathology, University of Alabama Medical Center, 1919 Seventh Avenue South, Birmingham, Alabama 35233, U.S.A. of persistent intermittent frontal headaches for $\stackrel{0}{\Phi}$ 옹 months and a psychiatric disorder of at least 15 yea duration. From the family history, we learned that the patient's father died of complications of what wass diagnosed as amyotrophic lateral sclerosis.

The patient's psychiatric problems started in the easi 1950s while he was in the Army. Here he was charged for not returning a borrowed car. Later, he began to live beyond his means, exhibited grandiose behaviour, and on at least one occasion tried to commit suicide. In 1959 he disappeared from home. When he returned 10 months later he was quiet and seclusive; however $\stackrel{0}{\square}$ he was still able to manage the farm and help his mother without great difficulty. In May 1968, the patient began $\overrightarrow{\bar{\sigma}}$ to lose weight. He developed right-sided headaches 3 which sometimes were severe and throbbing. He mani- $\overline{-}$ fested gradual mental deterioration, and was unable to recognize his brother in August 1968. He became suspicious and claimed that his neighbour put poison in his drinking water. Subsequently he was admitted to his local hospital where he complained of a frontal, throbbing headache, which was not aggravated by coughing, sneezing, straining, or change of head position. He denied venereal disease, but readily admitted that 3 he had had urethral stricture. At that time nothing of 0 significance was found on physical examination nor on the neurological examination save for disturbances of cortical function. In addition his blood count, urin-글 alysis, blood urea nitrogen, and blood sugar were normal; N radiographs of the chest and skull were negative; and ${ }^{\mathrm{T}}$ his electroencephalogram was slightly abnormal. A lumbar puncture was performed on 8 September $1968 \mathrm{CW}$ and the results are listed in Table 1. 
TABLE 1

SPINAL FLUID EXAMINATION ${ }^{1}$

\begin{tabular}{|c|c|c|c|c|c|c|}
\hline Date & $\begin{array}{l}\text { Pressure } \\
(m m C S F)\end{array}$ & $\begin{array}{l}\text { Cell count } \\
(/ \text { c.mm })\end{array}$ & $\begin{array}{c}\text { Protein } \\
(\mathrm{mg} / 100 \mathrm{ml} .)\end{array}$ & $\begin{array}{c}\text { Sugar } \\
(\mathrm{mg} / 100 \mathrm{ml} .)\end{array}$ & $\begin{array}{c}\text { Chloride } \\
(\mathrm{mg} / 100 \mathrm{ml} .)\end{array}$ & Colloidal gold \\
\hline \multicolumn{7}{|l|}{1968} \\
\hline $\begin{array}{l}8 \text { Sept. }^{2} \\
21 \text { Nov. }\end{array}$ & $\begin{array}{c}320 / 280 \\
70 / 65\end{array}$ & $\begin{array}{l}3 \text { polys. } \\
15 \text { polys. } \\
13 \text { lymphs. }\end{array}$ & $\begin{array}{l}62 \\
76\end{array}$ & 62 & $\begin{array}{l}123 \\
122\end{array}$ & 0011111000 \\
\hline $\begin{array}{l}16 \text { Dec. } \\
1969\end{array}$ & & 0 & 70 & 55 & 120 & 0111000000 \\
\hline $\begin{array}{l}20 \text { Feb. } \\
9 \text { Apr. }\end{array}$ & & $\begin{array}{l}\mathbf{0} \\
\mathbf{0}\end{array}$ & $\begin{array}{l}62 \cdot 5 \\
66\end{array}$ & 53 & & $\begin{array}{l}1223210000 \\
1233321000\end{array}$ \\
\hline
\end{tabular}

${ }^{1}$ Fluid was grossly clear on each occasion and dark field examinations were negative for spirochaetes. Several cultures and examinations for fungi and tubercle bacilli were also negative.

${ }^{2}$ Lumbar puncture was performed at the local hospital.

PHYSICAL EXAMINATION On admission to our hospital he was disorientated, his attention span was short, and his judgement and recent memory inpaired. Intellect appeared to be poor. He mumbled and frequently talked to himself. Otherwise, the physical and neurological examinations remained negative.

LABORATORY FINDINGS The haematocrit was $37 \%$ and the white cell count 13,800 per c.mm with $80 \%$ neutrophils, $13 \%$ lymphocytes, $6 \%$ monocytes, and $1 \%$ basophils. The erythrocyte sedimentation rate, fasting blood sugar, urea nitrogen, serum electrolytes, creatinine, uric acid, calcium and phosphorus levels, alkaline and acid phosphatase, protein-bound iodine, and liver function profile were all within normal limits. A routine urinalysis was negative. The urine was also negative for porphobilinogen and metachromatic granules. The urine lead excretion was $0.2 \mathrm{mg} / \mathrm{l}$. per 24 hours and arsenic compound was not found in the hair and nails. Serial determinations of the serological reactions to syphilis were performed and the findings listed in Table 2. Several spinal punctures were done during his hospital-

TABLE 2

SUMMARY OF SEROLOGICAL REACTIONS

\begin{tabular}{|c|c|c|c|c|}
\hline \multirow[t]{2}{*}{ Date } & \multicolumn{3}{|c|}{ Blood } & \multirow{2}{*}{$\frac{C S F}{V D R L}$} \\
\hline & $V D R L$ & $R P C F$ & $F T A-A B S$ & \\
\hline $\begin{array}{l}1968 \\
4 \text { Sept. } \\
18 \text { Nov. } \\
1969 \\
28 \text { Jan. } \\
31 \mathrm{Jan} . \\
1 \mathrm{Feb} . \\
14 \mathrm{Feb} . \\
19 \mathrm{Feb} . \\
20 \mathrm{Feb} . \\
24 \mathrm{Feb} . \\
7 \mathrm{Mar} . \\
2 \mathrm{Apr} . \\
9 \mathrm{Apr} . \\
23 \mathrm{Apr} .\end{array}$ & $\begin{array}{c}\text { NR } \\
\mathbf{R} \\
\text { Started on p } \\
\mathbf{R} \\
\mathbf{R} \\
\mathbf{R} \\
\text { (4 dils) }\end{array}$ & $\begin{array}{c}\mathbf{R} \\
\mathbf{R} \\
\mathbf{R}\end{array}$ & $\begin{array}{c}\text { Brain biopsy } \\
\begin{array}{l}\mathbf{R} \\
\text { 1.2 M I.M. b.i.d. } \\
\text { R }\end{array}\end{array}$ & $\begin{array}{l}10 \text { days } \\
\text { NR }\end{array}$ \\
\hline
\end{tabular}

$\mathbf{R}=$ Reactive. $\quad \mathbf{N}=$ Non-reactive ization and the results were as shown in Table 1 . Routine radiographs of chest, skull, and upper cervical spine were unremarkable. On 19 November 1968 a lumbar pneumoencephalogram showed slight dilatation of the ventricular system and slight widening of the subarachnoid sulci indicative of mild cerebral atrophy. The electroencephalogram was normal on 15 November 1968. Normal cerebrospinal fluid dynamics were demonstrated by intrathecal radioiodinated serum albumin (RISA) and serial brain scan. An oral cholecystogram was normal. Sensory and motor nerve conduction were within normal limits.

BRAIN BIOPSY On 28 January 1969 a biopsy of the right frontal lobe of the brain was performed by Dr. Robert L. White who found the arachnoidal membrane to be thickened and firm and the area of the brain visible appeared atrophic and gliotic.

Sections (two) of the brain biopsy showed meninges, cortex, and underlying white matter. The thickened meninges showed a diffuse infiltration by lymphocytes and plasma cells along with occasional macrophages containing haemosiderin (Figs. 1 and 2). Some of the blood vessels in the meninges as well as in the underlying cortex and white matter showed similar infiltration of their walls as well as a striking perivascular cuffing (Figs. 1, 3, 4). In addition, there was a marked neuronal degeneration and an increase in astrocytes and microglial cells in the cortex (Figs. 4 and 5).

A portion of the brain biopsy specimen was frozen for immunofluorescence studies. Cryostat sections were stained for treponema pallidum using an absorbed indirect fluorescent antibody technique. A spiral organism, which stained brightly, was found exhibiting perfect morphology compatible with treponema pallidum.

HOSPITAL COURSE During the entire hospital course the patient manifested severely disturbed cortical function, otherwise the examination was completely negative. Two days after the brain biopsy, the patient developed a focal seizure which was subsequently controlled by phenobarbitone. On 19 February 1969, in view of the positive serological test and the brain biopsy findings, a 10 day course of penicillin, totalling 24 million units, was given. The patient's condition remained unchanged and he was later transferred back to his local hospital. 


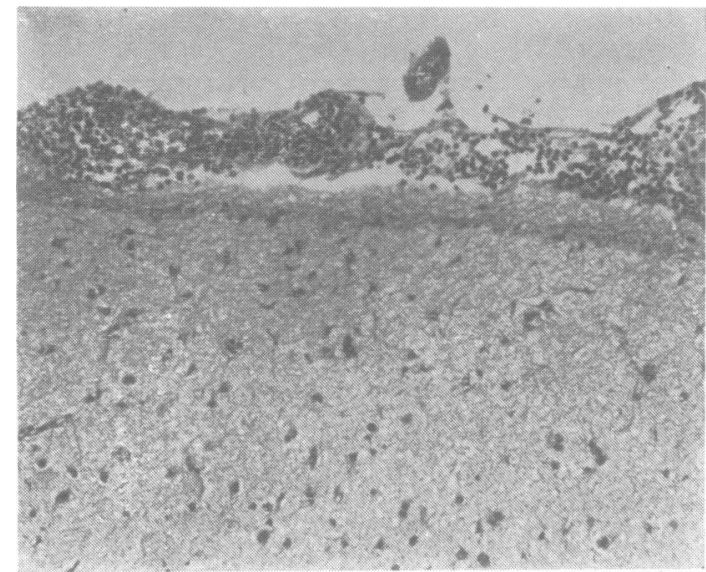

FIG. 1. Meningeal thickening and inflammatory infiltrate. $H$ and $E$, $\times 62$.

\section{DISCUSSION}

In the past few years there has been renewed interest in syphilis, chiefly because of the increased incidence of the disease despite the availability of modern treatment and preventive measures. It is alarming that nearly half of the recent cases occurred in teenagers and young adults, and reported cases of infectious syphilis among teenagers have increased as estimated in 1966 by more than $213 \%$ since 1956 (Olansky and Norins, 1966).

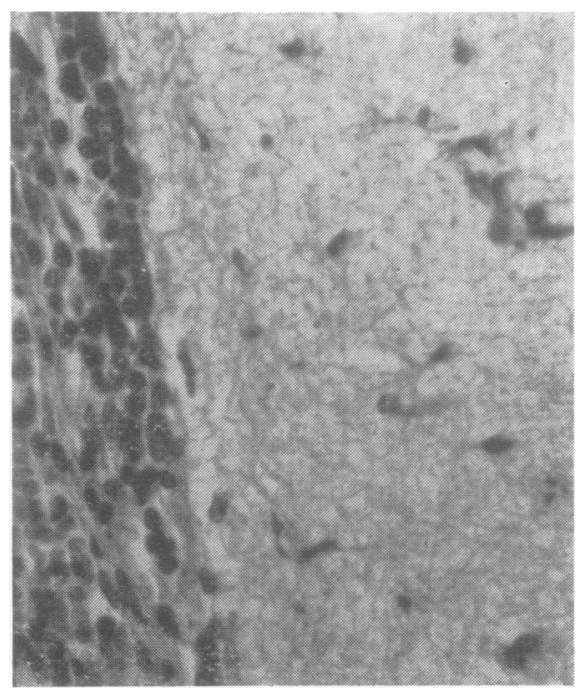

FIG. 2. Meninges: perivascular and vascular infiltration by lymphocytes and plasma cells. $H$ and $E, \times 240$.

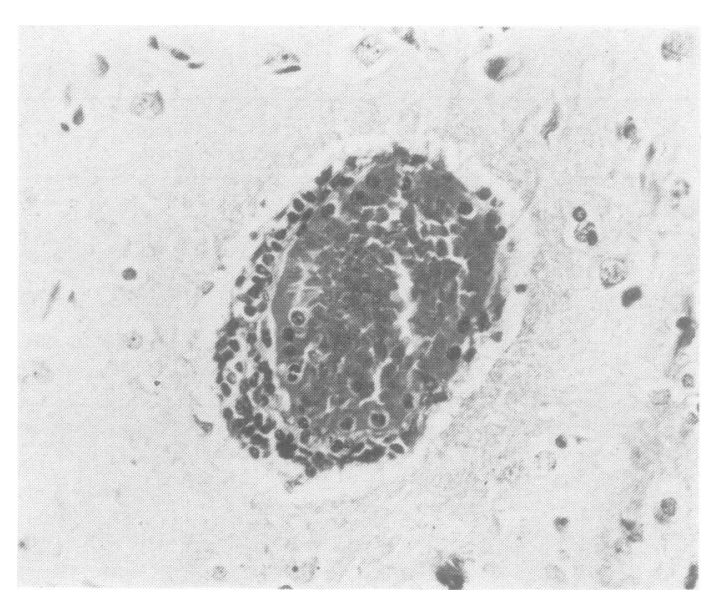

FIG. 3. Perivascular inflammatory infiltrate in cortex. $H$ and $E, \times 160$.

We can expect to encounter more and more cases of syphilis involving the central nervous system including dementia paralytica in the youngero age group.

The history of the demented patient is ofte unreliable or unobtainable and the cerebrospina 9 을 fluid findings often vary (Table 1). As a resultthe specific clinical diagnosis of the disease has to depend heavily on the serological findings.

The different types of serological tests used a aids in the diagnosis of syphilis may be classifie as non-treponemal and treponemal tests. Among the non-treponemal tests, the VDRL is one of the most commonly used tests for the detection of reagin in human serum by using non-specific

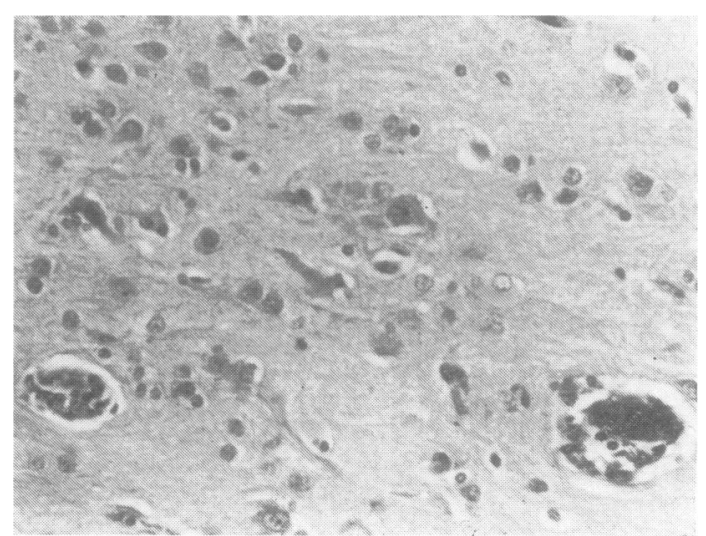

FIG. 4. Increase in astrocytes and microglia with perivascular infiltrate. $H$ and $E, \times 80$. 


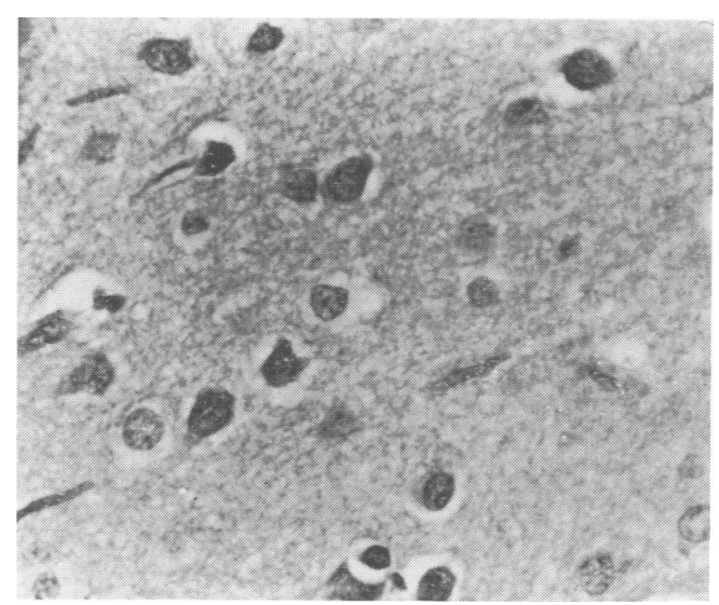

FIG. 5. 'Rod cells' and astrocytes in cortex. $H$ and $E$, $\times 250$.

lipid antigens. In the early phases of latent syphilis (one to two years after infection) reagin titres may remain high, whereas several years later the titres are usually low. The sera of a considerable number of patients with late syphilis may be non-reactive to the non-treponemal tests (Olansky and Norins, 1966). Despite this, the test is still widely used as a screening device in many institutions including mental hospitals (Banks, 1968). For more specific purposes one must rely on tests utilizing a treponemal antigen. Treponemal tests, including TPI and FTA-ABS, are not designed for routine use. They are ordinarily reserved for diagnostic problems when requested by the clinician (Wallace, 1965). They cost more and are harder to do. However, the value of treponemal tests has been demonstrated by the remarkably uniform experience of different authors.

On evaluating the various tests for late syphilis, Huriez, Martin, and Baelden (1961) found only $77 \%$ of the TPI reactive patients had reactive VDRL tests and the findings of Wilkinson and Rayner (1966) were essentially the same-namely, only $78 \%$ of the patients with reactive TPI had detectable reagins. Harner, Smith, and Israel (1968) demonstrated that, among patients with late syphilis identified by the FTA-ABS test, only $61 \%$ were VDRL reactive. Smith and Taylor (1965) found seven patients with late syphilis whose sera were non-reactive to the VDRL and TPI tests; all seven had a reactive FTA-ABS. Tinkler (1968) reported an interesting case of a mother who had latent syphilis of long standing in whom the standard serum test for syphilis was negative. However, she gave birth to a congenital syphilitic baby. The serum FTA-ABS test, although by far the most reliable serological test for syphilis now available, is not infallible (Schroer and Civin, 1968). In fact, active neurosyphilis cannot be excluded from the differential diagnosis even if all the available serological tests are negative.

Earlier reports cast some doubts on the belief that spirochaetes may survive after penicillin therapy (Yobs, Rockwell, and Clark, Jr., 1964; Yobs, Olansky, Rockwell, and Clark, Jr., 1965). From more recent studies, it is apparent that spirochaetes can stay alive (Yobs, Clark, Jr., Mothershed, Bullard, and Artley, 1968) and late syphilis involving the central nervous system can develop in a person with initial subclinical infection or in a person whose treatment was considered adequate (Banks, 1968). Smith and Israel (1968) were able to demonstrate motile treponemes in the aqueous humor and treponemes by fluorescentantibody staining of a liver biopsy specimen from a patient with treated tabes on whose serum the FTA-ABS, TPI, and VDRL tests were all negative. It has been estimated that as many as 10 to $33 \%$ of patients with late active syphilis may have negative cardiolipin tests, and a significant number of patients may react negatively to both treponemal and non-treponemal tests. Therefore, there is ample reason to believe that many patients with dementia paralytica have escaped detection.

In a group of penicillin-treated general paretics, an unexpected high rate of central nervous system complications with new gross neurological abnormalities was found to develop long after the initial therapy (Wilner and Brody, 1968). The effectiveness of the penicillin therapy, in this patient, is uncertain without long-term follow-up.

\section{CONCLUSION}

From the case of seronegative active meningoencephalitis reported in this communication and the experiences of other authors, we believe a non-reactive non-treponemal test result is insufficient to exclude active late syphilis. When the FTA-ABS test becomes more widely available, we advise its use as a routine screening test in addition to the reagin test in all patients with neurological problems of possibly syphilitic origin. Further research in this field is, of course, urgently needed.

\section{REFERENCES}

Banks, G. D. (1968). The value of routine serological testing for syphilis in a mental hospital. Brit. J. Psychiat., 114, 113-114. 
Harner, R. E., Smith, J. L., and Israel, C. W. (1968). The FTA-ABS test in late syphilis. A serological study in 1,985 cases. J. Amer. med. Ass., 203, 545-548.

Huriez, C., Martin, P., and Baelden, J. (1961). Exploration immuno-allergologique dans la syphilis tardive. Intéret du test à la luétine. Lille méd., 6, 178-183.

Olansky, S., and Norins, L. C. (1966). Current serodiagnosis and treatment of syphilis. J. Amer. med. Ass., 198, 165-168.

Schroer, J. A., and Civin, W. H. (1968). Evaluation of fluorescent treponemal antibody absorption test in the diagnosis of syphilis. Cincinn.J. Med., 49, 335-337.

Smith, J. L., and Israel, C. W. (1968). Recovery of spirochaetes in the monkey by passive transfer from human late seronegative syphilis. Brit. J. vener. Dis., 44, 109-115.

Smith, J. L., and Taylor, W. H. (1965). The FTA-ABS test in ocular and neurosyphilis. Amer. J. Ophthal., 60, 653-658.

Tinkler, A. E. (1968). Sero-negative maternal syphilis. Brit. J. vener. Dis., 44, 136-139.
Wallace, A. L. (1965). Trends and uses of various tests in 으 syphilis serology today. Amer. J. clin. Path., 44, Z 712-719.

Wilkinson, A. E., and Rayner, C. F. A. (1966). Studies on the fluorescent treponemal antibody (FTA) test. Brit.J. vener. Dis., 42, 8-15.

Wilner, E., and Brody, J. A. (1968). Prognosis of general paresis after treatment. Lancet, 2, 1370-1371.

Yobs, A. R., Clark, J. W., Jr., Mothershed, S. E., Bullard, $\frac{\Im}{\partial}$ J. C., and Artley, C. W. (1968). Further observations on the persistence of treponema pallidum after treatment in rabbits and humans. Brit. J. vener. Dis., 44, 116-130.

Yobs, A. R., Olansky, S., Rockwell, D. H., and Clark, J. W., Jr. (1965). Do treponemes survive adequate treatment of late syphilis? Arch. Derm., 91, 379-389.

Yobs, A. R., Rockwell, D. H., and Clark, J. W., Jr. (1964). Treponemal survival in humans after penicillin $\mathbb{\mathbb { Q }}$ therapy. A preliminary report. Brit. J. vener. Dis., 40, 248-253.

\section{The April 1970 Issue}

\section{THE APRIL 1970 ISSUE CONTAINS THE FOLLOWING PAPERS}

The nosological position of concentric lacunar leucoencephalopathy S. CURRIE, A. H. ROBERTS, and H. URICH

Ischaemic lacunae in the spinal cord of arteriosclerotic subjects C. FIESCHI, A. GOTTLIEB, and V. DE CAROLIS

Mineralization of the central nervous system in pseudopseudohypoparathyroidism (PPH) ALDEN W. DUDLEY JR. and HAL HAWKINS

Neurological and psychiatric manifestations in idiopathic hypoparathyroidism; response to treatment M. HOSSAIN

Anterior transposition of the ulnar nerve: an electrophysiological study J. PAYAN

Spurious papilloedema and visual field contraction after head trauma ROBERT T. DALE and MILES A. GALIN

Mucocoele of the sphenoidal sinus as a cause of recurrent oculomotor nerve palsy GEORGE FRIEDMANN and SPENCER HARRISON

A taxonomic study of physiological responses to a psychological stress P. K. BRIDGES, M. T. JONES, and D. LEAK

Psychiatric symptoms in Parkinsonism R. H. S. MINDHAM

Hypopituitarism (Sheehan's syndrome) presenting with organic psychosis S. M. HANNA

Neurological manifestations associated with internal carotid loops and kinks in children N. B. S. SARKARI, J. MACDONALD HOLMES, and EDWIN R. BICKERSTAFF
Radioactive brain scanning in the management of cere- $i$ brovascular disease JOHN MARSHALL and MARY $\epsilon_{\omega}$ POPHAM

Calcified intracranial haematoma associated with chronबृ $\sigma$ subdural hygroma C. ARSENI and M. IACOB

Cerebellar medulloblastomata in adults: review of cases JOHN MILES and Y. S. BHANDARI

Cranial nerve palsies in tetanus: cephalic tetanus PARK

The quadriceps stretch reflex in human spasticity DAVID BURKE, J. D. GILLIES, and JAMES W. LANCE

Stereotactic cervical myelotomy EDWARD HITCHCOCK

The effect of diazepam on the EEG of status epilepticus D. S. BELL

Hereditary motor end-plate disease in the mouse: light and electron microscopic studies L. W. DUCHEN with a genetic appendix by A. G. SEARLE

'Meningoceles' and 'meningomyeloceles' (ectopic spinal cord) VASANT C. TALWALKER and DARAB K. DASTUR

Ossification in the region of the posterior longitudinal ligament as a cause of cervical myelopathy L. BAKAY, H. L. CARES, and R. J. SMITH

Effect of tryptophan administration on 5HIAA in cere- $O$ brospinal fluid in man D. ECCLESTON, G. W. ASHCROFT, T. B. B. CRAWFORD, J. B. STANTON, D. WOOD, and P. H.O MCTURK

Book Reviews

Copies are still available from the PUBLISHING MANAGER, BRITISH MEDICAL ASSOCIATION, TAVISTOCK SQUARE, WC1H 9JR, price 21 s. 